\title{
Article \\ Olive Oils from Fruits Infected with Different Anthracnose Pathogens Show Sensory Defects Earlier Than Chemical Degradation
}

\author{
Fátima Peres ${ }^{1,2} \mathbb{D}$, Pedro Talhinhas ${ }^{2}\left(\mathbb{D}\right.$, Hugo Afonso ${ }^{2}$, Helena Alegre ${ }^{2}$, Helena Oliveira ${ }^{2}$ and \\ Suzana Ferreira-Dias $2, *$ (D) \\ 1 Instituto Politécnico de Castelo Branco, Escola Superior Agrária, 6000-909 Castelo Branco, Portugal; \\ fperes@ipcb.pt \\ 2 LEAF, Linking Landscape, Environment, Agriculture and Food, Instituto Superior de Agronomia, \\ Universidade de Lisboa, 1349-017 Lisbon, Portugal; ptalhinhas@isa.ulisboa.pt (P.T.); \\ hugoafonso95@gmail.com (H.A.); helenalegre@isa.ulisboa.pt (H.A.); heloliveira@isa.ulisboa.pt (H.O.) \\ * Correspondence: suzanafdias@mail.telepac.pt
}

check for updates

Citation: Peres, F.; Talhinhas, P.; Afonso, H.; Alegre, H.; Oliveira, H.; Ferreira-Dias, S. Olive Oils from Fruits Infected with Different Anthracnose Pathogens Show Sensory Defects Earlier Than Chemical Degradation. Agronomy 2021, 11, 1041. https://doi.org/ 10.3390/agronomy11061041

Academic Editor: Helder Fraga

Received: 29 April 2021

Accepted: 19 May 2021

Published: 22 May 2021

Publisher's Note: MDPI stays neutral with regard to jurisdictional claims in published maps and institutional affiliations.

Copyright: (c) 2021 by the authors. Licensee MDPI, Basel, Switzerland. This article is an open access article distributed under the terms and conditions of the Creative Commons Attribution (CC BY) license (https:/ / creativecommons.org/licenses/by/ $4.0 /)$.

\begin{abstract}
Anthracnose is the most important disease of olives responsible for olive oil depreciation. The aim of this study is to compare the negative effects of the most common olive anthracnose pathogens in Portugal, Colletotrichum nymphaeae, C. godetiae, or C. acutatum, on oil extracted from fruits of the most cultivated Portuguese olive cultivars, 'Galega Vulgar' and 'Cobrançosa'. Healthy fruits (ripening index 3.5) were inoculated, incubated, and sampled over 14 days post-inoculation (d.p.i.) for symptom assessment and oil extraction. Virgin olive oil (VOO) was characterised by quality criteria parameters (acidity, peroxide value, UV absorbances, organoleptic assessment, fatty acid ethyl esters (FAEE)), total phenols (TPH), main fatty acids, and waxes compositions. Galega Vulgar fruits were more susceptible to anthracnose than Cobrançosa fruits. Colletotrichum nymphaeae was equally highly virulent for both cultivars, while C. godetiae was less virulent especially in Cobrançosa. VOO acidity increased reached 5\% in Galega oils and 2\% in Cobrançosa oils from fruits infected with C. nymphaeae or C. acutatum at 14 d.p.i. FAEE were higher than the legal limit for extra VOO in Galega oils from fruits at 7 d.p.i. with C. nymphaeae or C. acutatum, or 11 d.p.i. with C. godetiae. TPH decreased through the experiments with all the inoculated fungi. The musty sensory defect was detected in Galega and Cobrançosa VOO from fruits inoculated with C. nymphaeae or C. acutatum at 3 or 7 d.p.i. earlier than chemical degradation, respectively. The degradation levels of olive oils depended on the Colletotrichum species and olive cultivar.
\end{abstract}

Keywords: olive anthracnose; Colletotrichum nymphaeae; Colletotrichum godetiae; Colletotrichum acutatum; fatty acid ethyl esters; olive oil; phenols; 'Cobrançosa'; 'Galega Vulgar'; sensory analysis

\section{Introduction}

Olive anthracnose, caused by diverse Colletotrichum species, is the most important fungal disease of olive fruits worldwide, leading to significant yield losses, fruit rot and drop and consequently poor olive oil quality. In the last decade, the recrudescence of olive anthracnose epidemics has been attributed in part to climate change related to increased relative humidity and rain levels in autumn and abnormal temperature fluctuations [1,2]. In addition to environmental conditions, the susceptibility of varieties and the virulence of the pathogen populations are decisive for the occurrence of epidemics [3-5]. The Mediterranean region is experiencing relevant changes in the frequency and distribution of the olive anthracnose pathogen populations as a consequence of global change [6,7].

The disease develops preferentially as fruits mature, concomitantly with autumn rains, and has a detrimental effect on olive oil quality by affecting its physicochemical and organoleptic properties [8-10]. For different cultivars, threshold levels for anthracnose incidence are established to obtain extra virgin olive oils (EVOO) [8,10]. 
Diverse species of the genus Colletotrichum may incite anthracnose symptoms in olive trees, most of them belonging to the "acutatum species complex" [6,11,12], each of which differs in virulence and geographic distribution [4]. In the Mediterranean Basin, C. godetiae is one of the most frequent species, but it seems to be in the process of being replaced by the highly virulent C. acutatum $[6,13]$. In Southwestern Iberia, the equally highly virulent $C$. nymphaeae is the most frequent species, coinciding to a large extent with the distribution area of 'Galega Vulgar', a cultivar present in five of the six Portuguese Protected Designation of Origin (PDO) for virgin olive oil (VOO) [14]. This cultivar is very susceptible to anthracnose [4,6]. In turn, 'Cobrançosa', which is considered moderately susceptible to the disease [5], with origin from NE Portugal where C. godetiae prevails [6,15], is becoming widespread in Portugal.

The identification of diverse species in the "acutatum species complex" as causal agents of olive anthracnose is recent, emerging as a consequence of the recognition of several species within what was previously known as "C. acutatum" and is now known as the "acutatum species complex", encompassing several species occurring on olives and many other hosts [12,16]. The aetiology of olive anthracnose has therefore changed profoundly in the last 2 decades and the use of names such as C. acutatum and C. gloeosporioides to designate the causal agents of olive anthracnose must be considered with caution and according to the date in which they were used. For instance, references to "C. acutatum" must be carefully considered to ascertain whether they refer to C. acutatum sensu lato, i.e., prior to the Damm et al. (2012) revision [16], or C. acutatum sensu stricto [12,16]. Members of the "acutatum species complex" differ in terms of their virulence towards olives and host cultivars respond differently to each species of the complex [4]. Thus, for each pathogenhost cultivar combination, it becomes important to determine the accurate disease aetiology, either to predict losses or to properly manage the disease.

Olive oils from fruits affected by anthracnose present chemical and sensory defects that may restrain their direct use as virgin oils [9]. The change of olive oil quality can be marked enough to result in a downgrading of the oil category from "extra virgin olive oil" to "virgin olive oil" or even to "lampante olive oil", with severe economic losses for the olive grower. However, the extent of the depreciation of olive oil and the parameters affected in each pathosystem (fungal species $x$ olive cultivar) are only partially known due to the lack of updates to the current taxonomic status in the genus Colletotrichum and the "acutatum species complex" in particular.

For several decades, olive oil quality has been assessed by chemical parameters (acidity, peroxide value, and UV absorbances) and sensory evaluation. However, since 2011, the European legislation [17] also started to consider the presence of fatty acid ethyl (FAEE) and methyl esters (FAME) in olive oil as quality parameters for EVOO. FAME and FAEE are non-volatile compounds that may be good indicators of the quality of olives and their oil, as methanol and ethanol are formed during olive fermentation. A high concentration of FAEE is considered by the EU legislation as an indicator of olive fermentation responsible for olive oil sensory defects [17]. In turn, the content of wax esters tends to increase through maturation, since olive pulp becomes softer. However, wax esters content is still not considered a conclusive indicator of oil degradation [18].

Phenol composition of VOO can give important information on its quality because phenols have an important impact on organoleptic evaluation since they are responsible for positive sensory attributes of bitterness and pungency, as well as on the biological value of olive oil due to the antioxidant effects of phenolic compounds [19-21]. Moreover, a health claim can be declared for EVOO if it contains more than $5 \mathrm{mg}$ of hydroxytyrosol and its derivatives per $20 \mathrm{~g}$ of oil [22]. The content of phenolic compounds in olives is a characteristic related to several factors, in which the cultivar and the state of ripeness of the fruit are of utmost importance [23]. Additionally, these compounds play an important role in fruit defence against abiotic and biotic stresses, including Colletotrichum spp. [24,25].

The ripening stage of olives is a critical factor for anthracnose development. Anthracnose pathogens affect more severely ripened than green fruits in which the concentration 
of phenolic compounds is higher than in mature fruits [10]. This suggests that higher concentrations of phenolic compounds in olive fruits may account for higher tolerance of some cultivars to the anthracnose pathogens [25-27]. Accordingly, early harvesting of the very susceptible cultivars is recommended to avoid secondary infections of ripe and overripe fruits [3] and their detrimental effects on olive oil quality.

The aim of the present study was to investigate, under controlled laboratory conditions, the effect of the most common olive anthracnose pathogens in Portugal, Colletotrichum nymphaeae, C. godetiae, and C. acutatum, on early ripened fruits from two Portuguese olive cultivars (Galega Vulgar and Cobrançosa), concerning olive oil quality and composition.

\section{Materials and Methods}

\subsection{Olive Characterisation}

Portuguese olive fruits (Olea europaea ssp. europaea var. europaea) of Cobrançosa and Galega Vulgar used in this study were produced according to organic production guidelines without the use of pesticides, in Beira Baixa Region, in a rainfed grove $\left(39^{\circ} 49^{\prime} 19^{\prime \prime} \mathrm{N}\right.$, $7^{\circ} 27^{\prime} 31^{\prime \prime} \mathrm{W}$ ). The climate of this region is classified as Csa (Mediterranean hot summer climate) according to the Köppen climate classification [28]. The annual accumulated precipitation of the year under study (2018) was $795 \mathrm{~mm}$, which is very similar to the average value in the period 1981-2010 for this region $(783.2 \mathrm{~mm}$ ) [29]. Olive fruits were picked in the first fortnight of November 2018. Their ripening indices (RI) were determined by following the guidelines of the International Olive Council (IOC) [30]; moisture and fat content of the fruits were evaluated by NIR (FOSS-Olivia, Hillerod, Denmark).

\subsection{Inoculation of Olives}

Healthy fruits (ripening index 3.5) from Galega Vulgar (fat content $\mathrm{dw}=36.63 \%$ and moisture content $=58.2 \%$ ) and Cobrançosa (fat content $\mathrm{dw}=32.0 \%$ and moisture content $=57.0 \%$ ) were selected for the present study. Fruits (approx. $10 \mathrm{~kg}$ ) of each cultivar were surface disinfected in $0.5 \% \mathrm{NaClO}$ for $1 \mathrm{~min}$, thoroughly rinsed in sterile distilled water and air-dried. Intact fruits of both cultivars were inoculated by spraying conidial suspensions $\left(10^{6}\right.$ spores $/ \mathrm{mL}$ ) of C. nymphaeae (isolate 18-006), C. godetiae (isolate 18-019), or C. acutatum (isolate 18-015) as previously described [4]. Fruits were incubated at $20^{\circ} \mathrm{C}$ and $100 \% \mathrm{RH}$ and samples $(2 \mathrm{~kg}$ ) were collected at $3,7,11$, and 14 days post-inoculation (d.p.i.) for symptom assessment ( $\%$ of fruits with symptoms) and olive oil extraction.

\subsection{Olive Oil Extraction}

Olive oils were extracted in a laboratory oil extraction system (Abencor analyser; MC2 Ingenieria y Sistemas S.L., Seville, Spain) under optimised conditions [31]. The olives were crushed with a hammer mill equipped with a $4 \mathrm{~mm}$ sieve at $3000 \mathrm{rpm}$. Malaxation of the pastes was performed at $27-30^{\circ} \mathrm{C}$, for $30 \mathrm{~min}$, and centrifugation at $3500 \mathrm{rpm}$ for $3 \mathrm{~min}$. After centrifugation, the olive oil was separated by settling in a graduated cylinder. Water traces in the oil were removed with anhydrous sodium sulfate, filtered through a cellulose filter, and stored in amber glass bottles at $4{ }^{\circ} \mathrm{C}$. For each batch, 3 independent extractions were performed.

\subsection{Chemical and Sensory Characterisation of Olive Oil}

Acidity value, peroxide value (PV), UV specific absorbances $\left(\mathrm{K}_{232}\right.$ and $\left.\mathrm{K}_{270}\right)$, and fatty acid ethyl esters (FAEE), which are considered by European Union as chemical quality criteria, were evaluated for each VOO sample. Acidity, PV, $\mathrm{K}_{232}$, and $\mathrm{K}_{270}$ and the major fatty acids (C16:0, C18:0, C18:1, and C18:2) were evaluated by NIR spectroscopy using a spectrometer (MPA, Bruker Optics, Ettlingen, Germany), using the calibration model B-Olive-Oil, Bruker Optics.

Samples of olive oils were also sensory evaluated by a panel test recognised by IOC. Quantitative Descriptive Analysis (QDA) is applied using a profile sheet that mainly considers the negative attributes (e.g., fusty, musty, muddy sediment, winey-vinegary, 
metallic, and rancid notes) which are the most commonly detectable negative attributes in virgin olive oils. Other defects described in the specific vocabulary can be named by means of designation to "others". The profile sheet also indicates fruity, bitter, and pungent sensations among positive notes. An unstructured scale, $10 \mathrm{~cm}$ long, is used to measure attributes intensity [32]. The methodology is described in Regulation No. 1348/2013 [33].

In the determination of the content of waxes, FAME and FAEE were performed according to the European Union official method [17] that is based on the addition of suitable internal standards to the oil and fractionation by liquid chromatography on a hydrated silica gel column. After recovery of the eluted fraction, capillary gas chromatography analysis was carried out using a GC-FID (PerkinElmer 8600) equipped with an on-column injector and a capillary column MEGA-5-HT (length $15 \mathrm{~m}$, internal diameter $0.32 \mathrm{~mm}$, film thickness $0.10 \mu \mathrm{m})$. The oven program temperature was: $80{ }^{\circ} \mathrm{C}$ for $1 \mathrm{~min}$, increasing by $20{ }^{\circ} \mathrm{C} / \mathrm{min}$ until reaching $140{ }^{\circ} \mathrm{C}$, increasing by $5{ }^{\circ} \mathrm{C} / \mathrm{min}$ until $335^{\circ} \mathrm{C}$, and maintaining for $20 \mathrm{~min}$. The detector temperature was at $350^{\circ} \mathrm{C}$ and the injection volume was $2.8 \mu \mathrm{L}$. Helium was used as the carrier gas with a flow of $1 \mathrm{~mL} / \mathrm{min}$.

Total phenols were extracted by liquid microextraction and were evaluated by VIS spectroscopy (JASCO 7800, Tokyo, Japan) according to Pizarro et al. [34]. Five hundred milligram of olive oil were extracted with $1 \mathrm{~mL}$ of a methanol/water mixture $(80: 20, v / v)$ in 2-mL Eppendorf reaction tubes. After vigorous shaking for $1 \mathrm{~min}$ using a vortex, the sample was centrifuged (Eppendorf MiniSpin Plus Microcentrifuges, Eppendorf, Madrid) at $13,400 \mathrm{rpm}$ for $5 \mathrm{~min}$ at $20^{\circ} \mathrm{C}$. This process was performed 3 times. The 3 extracts were mixed and the volume was adjusted to $5 \mathrm{~mL}$ with ultrapure water. The quantitative determination of phenolic content is based on the reaction of Folin-Ciocalteau reagent with the functional hydroxy groups of phenolic compounds. In the cuvette of $1 \mathrm{~cm}$ width, for spectrophotometric analysis, $0.1 \mathrm{~mL}$ of the aqueous-methanolic solution of phenolic compounds extracted from the VOO was diluted in $1.5 \mathrm{~mL}$ of ultrapure water, followed by the addition of $0.1 \mathrm{~mL}$ of Folin-Ciocalteau reagent and maintained for $3 \mathrm{~min}$. Then, $0.3 \mathrm{~mL}$ of $20 \%(w / v)$ sodium carbonate aqueous solution was added and mixed. The absorbance of the solution was measured after $1 \mathrm{~h}$ against a blank sample using a UV-VIS spectrophotometer at a wavelength of $765 \mathrm{~nm}$. The calibration curve was constructed using standard solutions of gallic acid. Results were expressed as milligram of gallic acid per kilogram of oil (mg GAE/kg).

\subsection{Statistical Analysis}

Statistical analysis was performed using the software Statistica ${ }^{\mathrm{TM}}$, version 7 , from Statsoft, Tulsa, OK, USA. A One-way ANOVA was performed on fatty acid composition and a post hoc Tukey test was used $(p \leq 0.05)$. Multivariate data analysis, namely Principal Component Analysis (PCA) and hierarchical Cluster Analysis (CA) were performed on datasets considering chemical and sensory results for VOO samples obtained from Galega Vulgar or Cobrançosa fruits submitted to different incubation times with different Colletotrichum fungi. PCA and CA are pattern-recognition techniques that will help to characterise the samples and to evaluate the presence of eventual groups, as well as identify the most important variables on sample characterisation. Euclidean distance, as a distance measurement between samples, and the single-linkage method were used in CA $[35,36]$.

\section{Results and Discussion}

\subsection{Olive Characterisation}

Figure 1 shows the evolution of anthracnose incidence along 14 days post-inoculation (d.p.i.) of Galega Vulgar and Cobrançosa fruits with C. acutatum, C. nymphaeae, or C. godetiae. Regardless of the cultivar and the inoculated isolate, disease symptoms were detected only at 7 d.p.i. with incidence increasing thereafter. Overall, the results showed that Galega Vulgar fruits are more susceptible to anthracnose than Cobrançosa fruits, as previously reported [4,5]. For both cultivars, C. nymphaeae and C. acutatum were equally virulent, while C. godetiae was less virulent, especially in Cobrançosa fruits. At 11 d.p.i., more 
than $90 \%$ of Galega Vulgar fruits inoculated with C. acutatum or C. nymphaeae presented anthracnose symptoms, while the disease incidence in Cobrançosa fruits was less than $60 \%$. Colletotrichum godetiae infected 76 and $88 \%$ of Galega Vulgar fruits against only 24 and $48 \%$ of Cobrançosa fruits at 11 and 14 d.p.i., respectively. Cuticle and exocarp thickness of Cobrançosa olives [37], cell wall composition [38], as well as the high phenolic content reported for Cobrançosa fruits $[39,40]$ can be positively related to higher fruit tolerance to anthracnose disease.

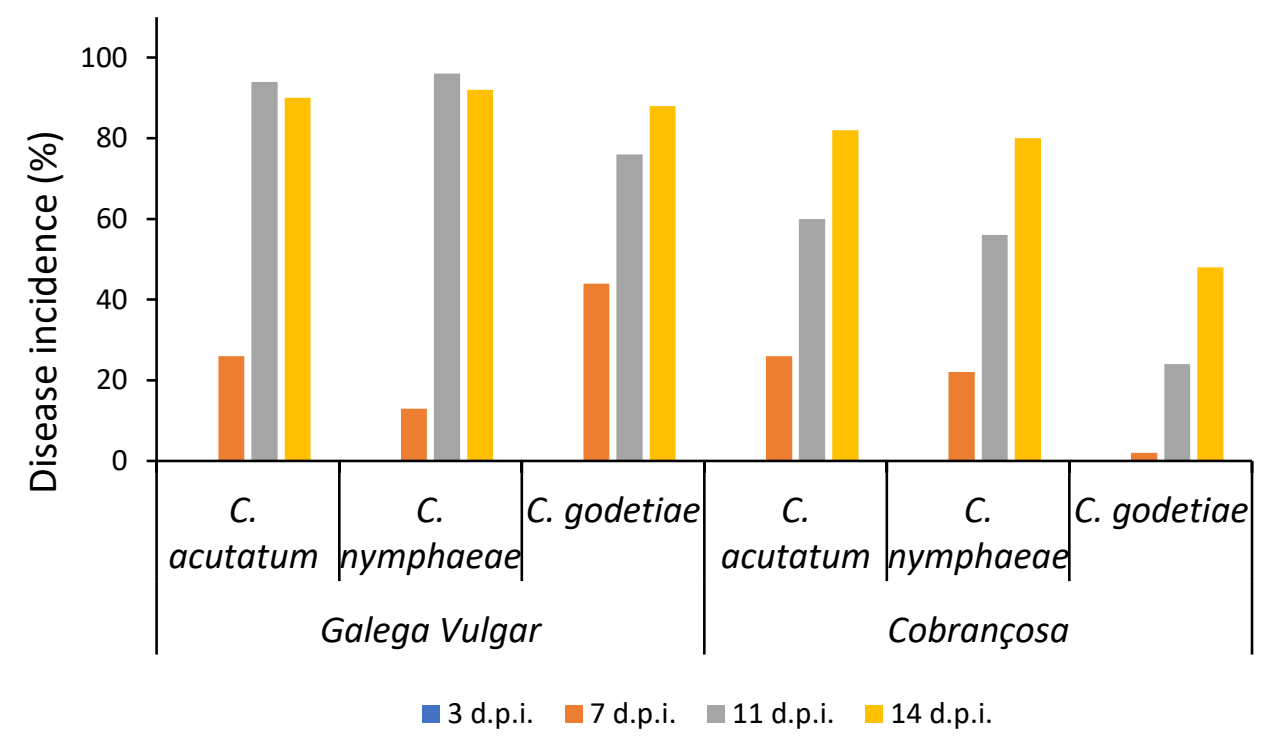

Figure 1. Evolution of anthracnose disease (\% of fruits with symptoms) of Galega and Cobrançosa fruits, after 3, 7, 11, and 14 days post-inoculation (d.p.i.) with Colletotrichum acutatum, C. nymphaeae, and C. godetiae.

\subsection{Olive Oil Characterisation by Quality Criteria}

According to the European Union [41], acidity, peroxide value, UV absorbances, FAEE, and sensory evaluation are considered quality criteria. Commercial virgin olive oils are classified as EVOO and $\mathrm{VOO}$ according to their quality parameter values. Respectively, seven (EVOO) and six (VOO) parameters are evaluated to check conformity with the declared category (Table 1). These parameters were evaluated for all VOO extracted from the fruits inoculated with each fungus to assess the effect of anthracnose severity on VOO quality.

Table 1. Acidity, peroxide value (PV), UV absorbances $\left(\mathrm{K}_{270}, \mathrm{~K}_{232}\right.$, and delta-K) and fatty acid ethyl esters (FAEE) quality characteristics for Galega and Cobrançosa oils at the beginning of experiments (t0) and the legal limits for commercial virgin olive oils (Extra Virgin Olive Oil (EVOO) and Virgin Olive Oil (VOO).

\begin{tabular}{ccccc}
\hline \multirow{2}{*}{ Quality Criteria } & \multicolumn{2}{c}{ Olive Oils } & \multicolumn{2}{c}{ Olive Oil Category [41] } \\
\cline { 2 - 5 } & Galega & Cobrançosa & EVOO & VOO \\
\hline Acidity (\% oleic acid) & 0.04 & 0.04 & $\leq 0.8$ & $\leq 2.0$ \\
PV (meq O $\mathrm{kg}^{-1}$ ) & 6.26 & 10.18 & $\leq 20$ & $\leq 20$ \\
$\mathrm{~K}_{270}$ & 0.19 & 0.14 & $\leq 0.22$ & $\leq 0.25$ \\
$\mathrm{~K}_{232}$ & 1.59 & 1.67 & $\leq 2.50$ & $\leq 2.60$ \\
Delta-K & $\leq 0.01$ & $\leq 0.01$ & $\leq 0.01$ & $\leq 0.01$ \\
Median of defect $(\mathrm{Md})$ & 0 & 0 & $\mathrm{Md}=0.0$ & $\mathrm{Md} \leq 3.5$ \\
Fruity median $(\mathrm{Mf})$ & 5.0 & 5.8 & $\mathrm{Mf} \geq 0$ & $\mathrm{Mf} \geq 0$ \\
FAEE $(\mathrm{mg} / \mathrm{kg})$ & 6 & 4 & $\leq 35$ & \\
\hline
\end{tabular}




\subsubsection{Chemical Parameters}

Olive oil acidity, resulting from acylglycerol hydrolysis, exponentially increased with d.p.i. for both cultivars (Figure 2). Again, for the same d.p.i. and fungus, the acidity (\% free fatty acid (\% FFA)) of Galega VOO was higher than for Cobrançosa VOO. At the end of the experiments (14 d.p.i.), olive oil acidity reached ca. $5 \%$ in Galega Vulgar and ca. $2 \%$ in Cobrançosa from olives infected with C. nymphaeae or C. acutatum.

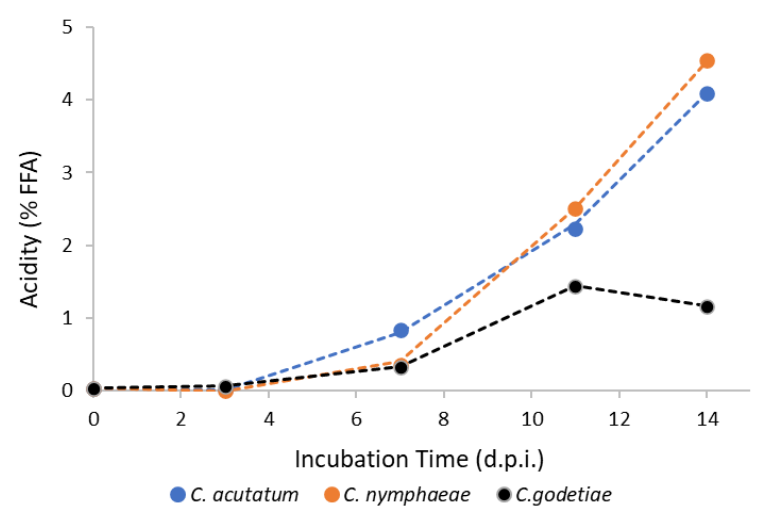

(a)

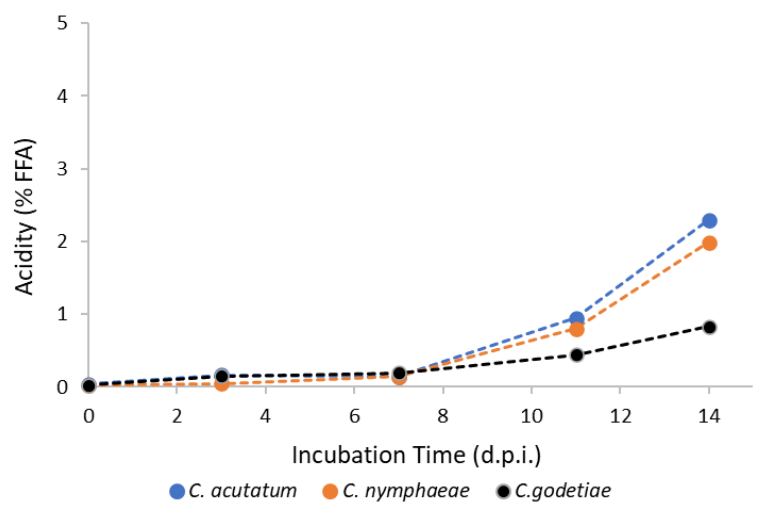

(b)

Figure 2. Acidity (\% Free Fatty Acids) of Galega (a) and Cobrançosa VOO (b) obtained from fruits, after 3, 7, 11, and 14 days post-inoculation (d.p.i.) with Colletotrichum acutatum, C. nymphaeae and C. godetiae (STD variation range: 0.01-0.03; not seen in the figures).

For Galega VOO, at 7 d.p.i., its acidity exceeds the legal limit for the commercial category EVOO (Table 1) for fruits inoculated with C. acutatum (disease incidence $26 \%$ ). By contrast, at 7 d.p.i., C. godetiae, which caused the highest disease incidence (44\%), was unable to increase the acidity of the oil to levels incompatible with the EVOO category. An intermediate behaviour was registered for C. nymphaeae (Figure 2). At 11 d.p.i., all isolates (disease incidence ranging from 76-96\%) caused an increase in the olive oil acidity to values above $0.8 \%$, up to a maximum of $2.51 \%$ (C. nymphaeae). Consequently, these oils fall into

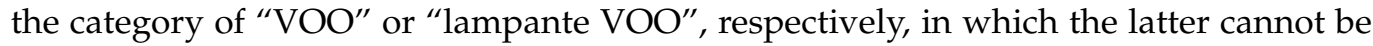
consumed as virgin olive oil [41].

Concerning Cobrançosa VOO, the effects on acidity at 7 d.p.i. can be neglected, even when oil is extracted from olives with a disease incidence similar to that of Galega Vulgar (Figure 2, e.g., C. acutatum). At 11 d.p.i., the acidity of olive oils resulting from fruits inoculated with C. acutatum (disease incidence $60 \%$ ) or C. godetiae (disease incidence $24 \%$ ) was higher than $0.8 \%$ but lower than $2.0 \%$ (VOO category), while the acidity of the oil resulting from fruits inoculated with C. nymphaeae (disease incidence 56\%) was lower than the legal limit for the EVOO category. At 14 d.p.i., regardless of the inoculated isolates, the acidity of the Cobrançosa oils obtained never reached values within the "lampante VOO" category [41].

The acidity of VOO showed to depend both on the susceptibility of the cultivar and on the virulence of distinct Colletotrichum species, which might be related to the ability of these fungi to produce lipases to catalyse olive oil hydrolysis.

All VOO samples showed Peroxide values (PV: 4-10.8 meqO $\mathrm{O}_{2} / \mathrm{kg}$ ) and UV absorbance values $\left(K_{232}\right.$ : 1.14-1.74.; $K_{270}$ : 0.07-0.19), which are lower than the maximum allowed for edible VOO (Table 1), indicating that VOO oxidation during fruit incubation did not occur in large extent. Therefore, this suggests that the production of enzymes responsible for olive oil oxidation by the Colletotrichum species used in this study occurs to a limited extent. Similar results were observed by Leoni et al. [10], with 'Arbequina' and 'Frantoio' fruits inoculated with C. acutatum. 
FAEE and FAME reflect the action of fermentative microorganisms on olives. The European Union established the limit of $35 \mathrm{mg}$ of ethyl esters per $\mathrm{kg}$ of oil for the EVOO category [41].

The contents of FAME and FAEE of Galega and Cobrançosa VOO obtained from fruits inoculated with each isolate, as a function of d.p.i., are presented in Figure 3. Again, Galega olive oils showed higher amounts of methyl and ethyl esters than Cobrançosa olive oils, but this varies according to the fungal species. At 14 d.p.i., the highest contents of FAEE and FAME were observed in Galega VOO from fruits inoculated with C. acutatum (160 mg/ $\mathrm{kg}$ oil) and C. nymphaeae $(984.5 \mathrm{mg} / \mathrm{kg}$ oil), respectively. At the end of the experiments, FAEE contents in Galega VOO reached values between 1.3 (C. nymphaeae) and 5.7 times (C. godetiae) the values attained in Cobrançosa VOO, respectively with the same pathogens. FAME contents in Galega VOO at 14 d.p.i. reached values 10 times higher than in Cobrançosa VOO with C. nymphaeae, 8.2 times higher with C. godetiae and 3.2 times the value with $C$. acutatum.

FAEE contents in Galega olive oils from fruits at 7 d.p.i. with C. acutatum or C. nymphaeae ( 65 and $62 \mathrm{mg} / \mathrm{kg}$ oil, respectively) were higher than the legal limit for EVOO (35 mg/kg oil). When Galega Vulgar fruits were inoculated with C. godetiae, FAEE were higher than the legal limit only at 11 d.p.i. ( $38 \mathrm{mg} / \mathrm{kg}$ oil). For Cobrançosa olive oils, the amounts of FAME and FAEE were similar, for each Colletotrichum species. At 14 d.p.i. with C. acutatum or C. nymphaeae, Cobrançosa oils had more than the legal limit for FAEE in EVOO (79 and $107 \mathrm{mg} / \mathrm{kg}$ oil, respectively), while the oils extracted from olives inoculated with C. godetiae only had $15 \mathrm{mg} / \mathrm{kg}$ oil.
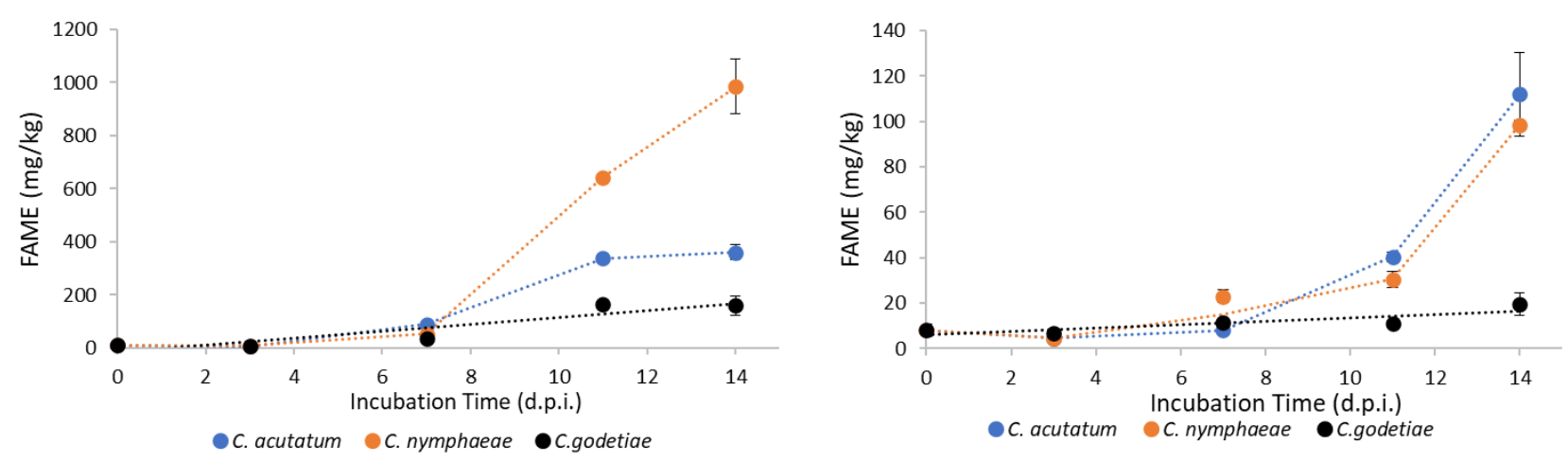

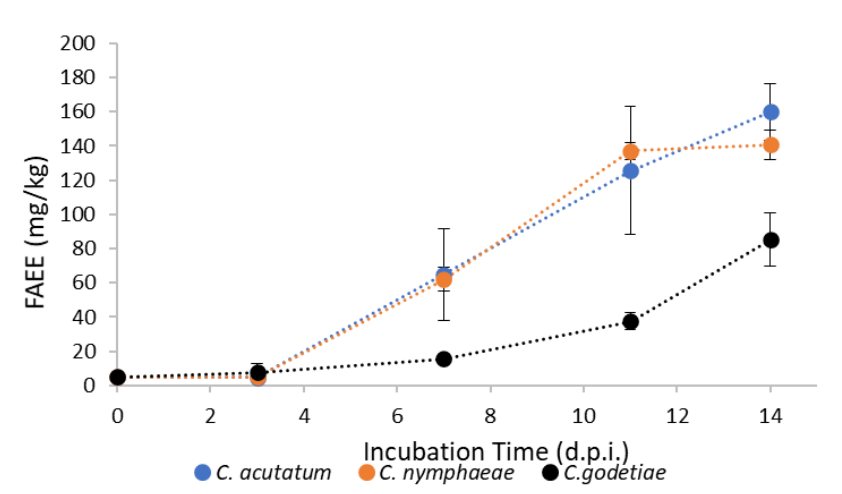

(a)

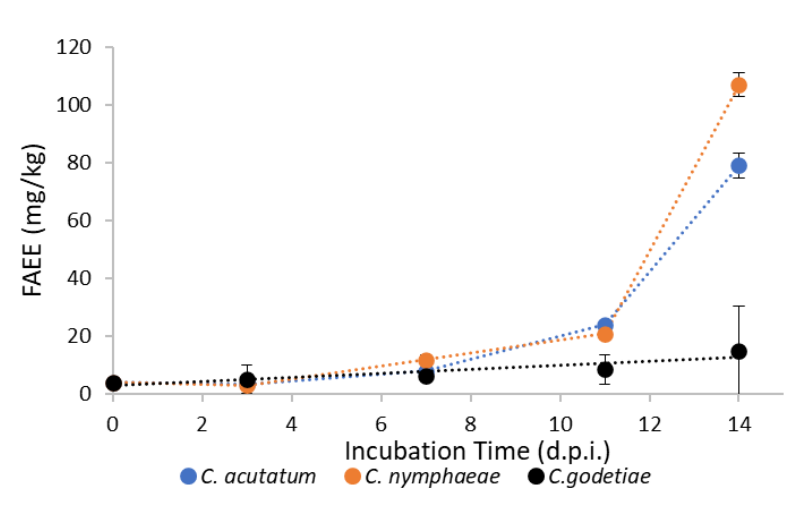

(b)

Figure 3. Total amount of FAME and FAEE of Galega (a) and Cobrançosa VOO (b) obtained from fruits, after 3, 7, 11, and 14 days post-inoculation (d.p.i.) with Colletotrichum acutatum, C. nymphaeae, and C. godetiae (mean values \pm STD).

The effect of each Colletotrichum species, as assessed by FAEE production in Galega and Cobrançosa oils, shows the following order: C. nymphaeae $\sim$ C. acutatum $>$ C. godetiae. This may be correlated with the lesser virulence reported for $C$. godetiae and the occurrence 
of interaction between the most virulent pathogens (C. acutatum and C. nymphaeae) for both cultivars [4].

Wax content $(C 42+C 44+C 46)$ of olive oils was always lower than the maximum legal limit of $150 \mathrm{mg} / \mathrm{kg}$ of waxes for the EVOO category [41]. Galega VOO presented an average wax content of $98.4 \mathrm{mg} / \mathrm{kg}$, varying from 67.1 and $140.7 \mathrm{mg} / \mathrm{kg}$. The wax content of Cobrançosa VOO ranged from 40.9 to $71.9 \mathrm{mg} / \mathrm{kg}$, with an average value of $64.6 \mathrm{mg} / \mathrm{kg}$. Thus, Galega olive oils always showed higher contents of waxes than Cobrançosa VOO. For each cultivar, no relationship was observed between wax content and anthracnose disease. In fact, high values of wax content have multiple causes and, as a consequence, is not a good indicator of the degradation of olive fruits [18].

\subsubsection{Sensory Analysis}

All VOO were sensory evaluated by a trained panel to detect and quantify both negative and positive attributes of VOO. According to the EU Regulations [41], "extra virgin olive oils" must present a median of sensory defects equal to zero and a fruity flavour median higher than zero. For the commercial category of "virgin olive oil", the median of defects may be $\leq 3.5$ and the fruity flavour median higher than zero (Table 1 ). The median of the defects is assumed as the median value of the defect which is present at the highest intensity. In the case of olives damaged by anthracnose, a significant increase of aldehydes such as heptanal, octanal, and nonanal was reported [42] due to the decomposition reactions of hydroperoxides formed by the auto-oxidation of unsaturated fatty acids [43]. Figure 4 shows the median of the "musty" defect of Galega and Cobrançosa VOO obtained from fruits at 3, 7, 11, and 14 d.p.i. with C. acutatum, C. nymphaeae, and C. godetiae. The musty defect was detected in Galega VOO obtained from fruits inoculated with C. acutatum or C. godetiae at 3 d.p.i., or at 7 d.p.i. with C. nymphaeae. With Cobrançosa fruits, the perception of musty defect occurred only at 11 d.p.i. with all fungi. However, the intensity of the defect was lower in oils from fruits infected with C. godetiae. Moreover, the musty defect detected in the oils was accompanied by the presence of winey defect but always in lower intensity. The presence of musty defect has been ascribed to the development of filamentous fungi and yeasts, while the attribute "winey/vinegary" is basically due to the formation of acetic acid, ethyl acetate, and ethanol by olive fermentation $[32,44,45]$.

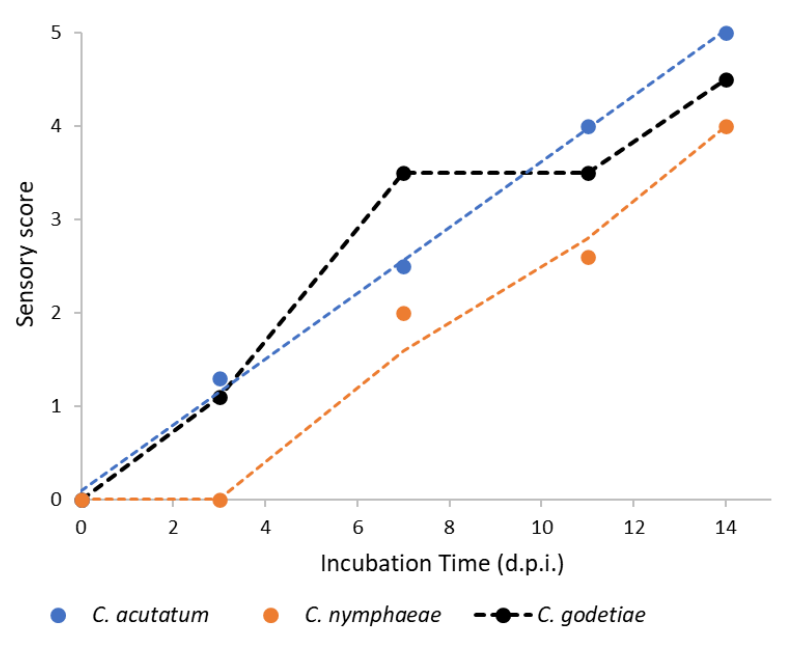

(a)

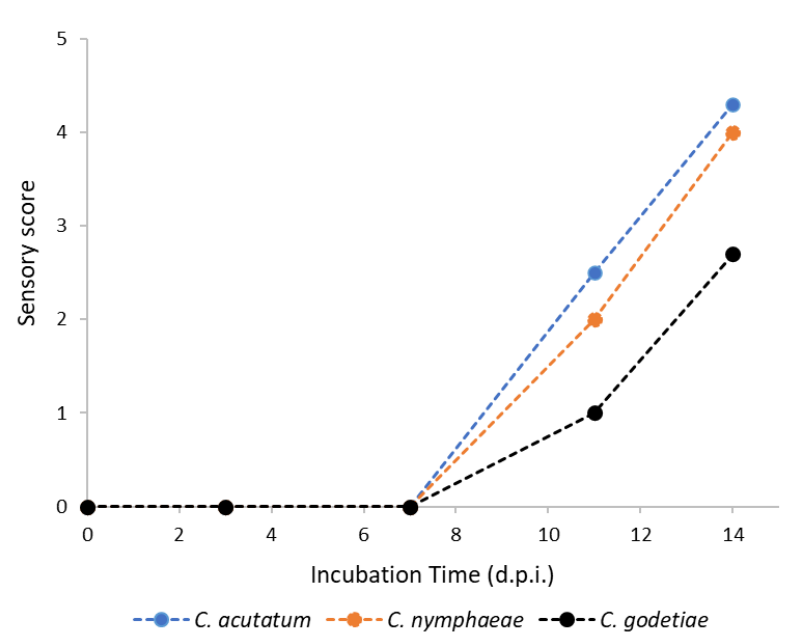

(b)

Figure 4. Musty defect score detected in Galega (a) and Cobrançosa VOO (b) obtained from fruits, after 3, 7, 11, and 14 days post-inoculation (d.p.i.) with Colletotrichum acutatum, C. nymphaeae, and C. godetiae.

The observed behaviour for Cobrançosa may be due to the masking effect of bitterness and pungency of those VOO against the musty defect, as already reported by Leoni et al. (2018) [10]. 
Figure 5 shows the decrease in the intensity of positive attributes (fruity, bitter, and pungent) as the intensity of negative attributes increases in Galega or Cobrançosa VOO from fruits inoculated with C. acutatum. Similar profiles were observed with the VOO when C. nymphaeae or C. godetiae were considered.

The perceived defects result from the fungal/microbial activity of the inoculated fungi on olive fruits throughout the incubation period. The intensity of positive attributes in Galega VOO showed a faster decrease than in Cobrançosa oils, which may be explained by a faster increase in the intensity of sensory defects. The detection of sensory defects occurred in olive oil samples with less than $0.8 \%$ FFA or $35 \mathrm{mg}$ FAEE $/ \mathrm{kg}$, which are the legal limits for the EVOO category [41]. Therefore, the sensory evaluation was more sensitive than chemical analysis to assess olive oil quality. This finding is not uncommon, because other kinds of defects eventually not covered by chemical analysis can be evidenced during the organoleptic evaluation [46].

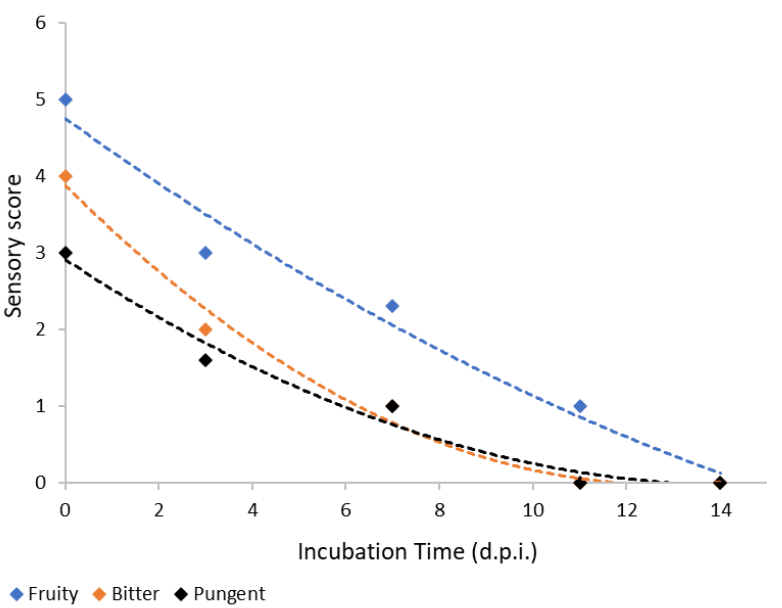

(a)

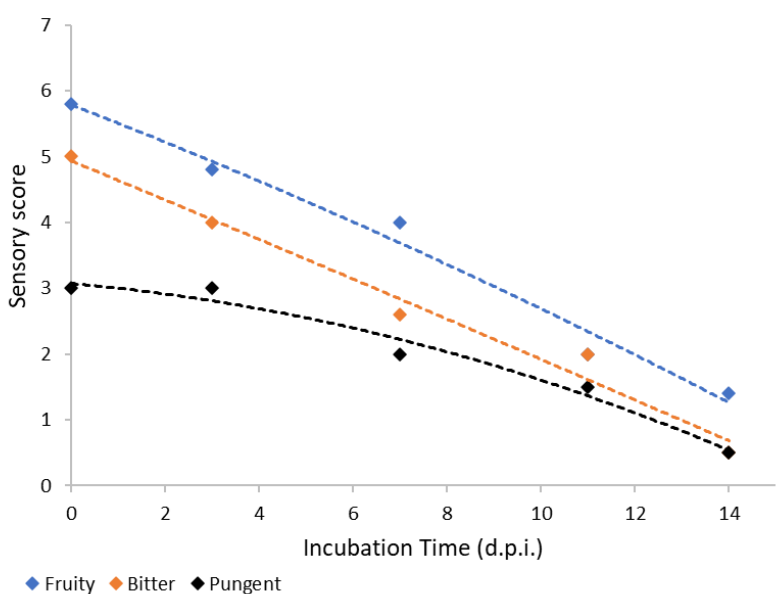

(b)

Figure 5. Sensory scores for positive (fruity, bitter, and pungent) attributes detected in Galega (a) and Cobrançosa VOO (b) obtained from fruits, at times $0,3,7,11$, and 14 days post-inoculation (d.p.i.) with Colletotrichum acutatum.

\subsection{Fatty Acid Composition}

The four major fatty acids in olive oil (palmitic, stearic, oleic, and linoleic acids) were quantified in all samples and the results are presented in Table 2. The extent of anthracnose infection does not seem to have noticeable effects on the major fatty acid components of Galega or Cobrançosa olive oils.

Both oils had similar contents of oleic acid: $74.1 \%$ on average in Galega (ranging from 72.98 to $75.53 \%$ ) and $73.24 \%$ in Cobrançosa oils (ranging from 72.15 to $73.79 \%$ ). Palmitic acid content, the major saturated fatty acid, has an average value of 15.1 and $13.84 \%$ in Galega and Cobrançosa olive oils, respectively. However, for all Galega and Cobrançosa VOO obtained from fruits incubated with each fungus, a significant increase in linoleic acid (C18:2) was observed along the incubation period (Tukey test; $p \leq 0.05)$. For other hostfungal interactions, the accumulation of linoleic acid (C18:2) was suggested to be an early component of the complex of responses associated with a defence against pathogens [47]. This may be explained by increased desaturation of stearic (C18:0) and oleic (C18:1) fatty acyl chains to form phospholipids containing linoleic (C18:2) acyl chains. Additionally, in the C. gloeosporioides-avocado interaction, the increase of linoleic acid, after elicitation with the pathogen, was attributed to enhanced $\Delta^{-9}$ stearoyl-ACP desaturase expression, which not only participates in a pathway leading to antifungal diene formation but also regulates this pathway [48,49]. Although not covered in this work, the mechanism of accumulation of linoleic acid should be further investigated for olive cultivars-Colletotrichum species interactions. 
Table 2. Mean values of the major fatty acid composition (palmitic (C16:0), stearic (C18:0), oleic (C18:1), and linoleic acids (C18:2)) of Galega (GAL) and Cobrançosa (COB) VOO obtained from fruits inoculated with Colletotrichum acutatum (Ac), C. nymphaeae (Ny), and C. godetiae (Go), at $0,3,7,11$, and 14 days of incubation. Superscript indexes indicate significant differences between days of incubation for each cultivar and fatty acid based on a Tukey test $(p<0.05)$.

\begin{tabular}{ccccccccc}
\hline Fatty Acid & \multicolumn{2}{c}{ C16:0 (\%) } & \multicolumn{2}{c}{ C18:0 (\%) } & \multicolumn{2}{c}{ C18:2 (\%) } & \multicolumn{2}{c}{ C18:1 (\%) } \\
\hline Sample & GAL & COB & GAL & COB & GAL & COB & GAL & COB \\
\hline t0 & $14.99^{\mathrm{abc}}$ & $13.57^{\mathrm{bcde}}$ & $2.44^{\mathrm{a}}$ & $2.93^{\mathrm{cd}}$ & $5.14^{\mathrm{h}}$ & $6.23^{\mathrm{i}}$ & $75.53^{\mathrm{a}}$ & $73.76^{\mathrm{ab}}$ \\
\hline Ac3 & $14.74^{\mathrm{bc}}$ & $13.29^{\mathrm{cde}}$ & $2.45^{\mathrm{a}}$ & $2.90^{\mathrm{cd}}$ & $5.85^{\mathrm{f}}$ & $6.87^{\mathrm{fh}}$ & $74.69^{\mathrm{bc}}$ & $73.79^{\mathrm{a}}$ \\
Ac7 & $15.65^{\mathrm{ab}}$ & $13.20^{\mathrm{de}}$ & $2.43^{\mathrm{a}}$ & $2.97^{\mathrm{bcd}}$ & $6.42^{\mathrm{e}}$ & $6.69^{\mathrm{h}}$ & $73.60^{\mathrm{def}}$ & $73.66^{\mathrm{ab}}$ \\
Ac11 & $15.56^{\mathrm{ab}}$ & $13.90^{\mathrm{bc}}$ & $2.76^{\mathrm{a}}$ & $3.00^{\mathrm{abcd}}$ & $6.77^{\mathrm{d}}$ & $7.19^{\mathrm{e}}$ & $73.78^{\mathrm{de}}$ & $73.36^{\mathrm{abc}}$ \\
Ac14 & $15.61^{\mathrm{ab}}$ & $15.69^{\mathrm{a}}$ & $2.47^{\mathrm{a}}$ & $3.17^{\mathrm{a}}$ & $6.97^{\mathrm{c}}$ & $8.65^{\mathrm{b}}$ & $73.34^{\text {ef }}$ & $72.40^{\mathrm{d}}$ \\
Ny3 & $14.91^{\mathrm{abc}}$ & $13.53^{\mathrm{bcde}}$ & $2.36^{\mathrm{a}}$ & $2.82^{\mathrm{d}}$ & $5.44^{\mathrm{g}}$ & $6.68^{\mathrm{h}}$ & $75.09^{\mathrm{ab}}$ & $73.54^{\mathrm{abc}}$ \\
Ny7 & $14.70^{\mathrm{bc}}$ & $13.02^{\mathrm{e}}$ & $2.38^{\mathrm{a}}$ & $2.91^{\mathrm{cd}}$ & $5.93^{\mathrm{f}}$ & $6.84^{\mathrm{g}}$ & $74.10^{\mathrm{cd}}$ & $73.52^{\mathrm{abc}}$ \\
Ny11 & $15.92^{\mathrm{a}}$ & $13.66^{\mathrm{bcde}}$ & $2.31^{\mathrm{a}}$ & $3.03^{\mathrm{abc}}$ & $6.93^{\mathrm{e}}$ & $7.29^{\mathrm{de}}$ & $73.86^{\mathrm{de}}$ & $73.20^{\mathrm{c}}$ \\
Ny14 & $15.26^{\mathrm{abc}}$ & $15.30^{\mathrm{a}}$ & $2.67^{\mathrm{a}}$ & $3.14^{\mathrm{ab}}$ & $6.80^{\mathrm{d}}$ & $9.05^{\mathrm{a}}$ & $73.95^{\mathrm{de}}$ & $72.15^{\mathrm{d}}$ \\
Go3 & $14.74^{\mathrm{bc}}$ & $13.58^{\mathrm{bcde}}$ & $2.48^{\mathrm{a}}$ & $2.89^{\mathrm{cd}}$ & $7.20^{\mathrm{ab}}$ & $6.94^{\mathrm{f}}$ & $73.30^{\text {ef }}$ & $73.59^{\mathrm{abc}}$ \\
Go7 & $14.35^{\mathrm{c}}$ & $13.73^{\mathrm{bcd}}$ & $2.47^{\mathrm{a}}$ & $2.85^{\mathrm{cd}}$ & $7.25^{\mathrm{a}}$ & $7.36^{\mathrm{d}}$ & $73.31^{\text {ef }}$ & $73.23^{\mathrm{bc}}$ \\
Go11 & $14.88^{\mathrm{bc}}$ & $13.77^{\mathrm{bcd}}$ & $2.59^{\mathrm{a}}$ & $2.89^{\mathrm{cd}}$ & $7.12^{\mathrm{b}}$ & $8.14^{\mathrm{c}}$ & $73.39^{\text {ef }}$ & $72.66^{\mathrm{d}}$ \\
Go14 & $15.00^{\mathrm{abc}}$ & $14.19^{\mathrm{b}}$ & $2.60^{\mathrm{a}}$ & $2.94^{\mathrm{cd}}$ & $6.93^{\mathrm{c}}$ & $8.59^{\mathrm{b}}$ & $72.98^{\mathrm{f}}$ & $72.27^{\mathrm{d}}$ \\
\hline
\end{tabular}

\subsection{Phenol Contents}

The content of total phenols in Galega and Cobrançosa VOO along the experiments is presented in Figure 6. Cobrançosa VOO from healthy fruits presented a higher content of phenolic compounds $(1022 \mathrm{mg} / \mathrm{kg})$ than Galega $\mathrm{VOO}(700 \mathrm{mg} / \mathrm{kg})$. These results are in accordance with previous findings in which Cobrançosa oils showed a higher content of total phenols than Galega for a similar olive-ripening index (ca. 3.5) [23]. The higher constitutive content of phenolic compounds in Cobrançosa VOO (and fruits) as compared to Galega [27] may explain the higher tolerance to anthracnose disease usually reported for Cobrançosa cultivar, in which phenols are likely able to counteract the initial attack of Colletotrichum fungi on the fruits. Additionally, phenolic compounds are related to the defensive reactions of plants against pathogens [50], namely to anthracnose pathogens [51], either by the accumulation of pre-existing phenolic compounds or by de novo synthesis of defence chemicals [52]. However, our results show no increase of phenols in olive oils in response to the infection and indicate that the Colletotrichum spp. tested were not inhibited by these compounds. In fact, in the present study, the phenolic content in the oils from both cultivars decreased through the time post-inoculation (Figure 6). At the end of the experiments (14 d.p.i.), an 83-89\% reduction in the initial content of phenolic compounds of Cobrançosa VOO and an $84-93 \%$ reduction in Galega VOO were observed. The reduction of phenolic compounds content concomitantly with the increase of disease incidence and progress is in line with the recognised role of fungi in the biodegradation of natural phenolic compounds, most of them producing phenol oxidases [53,54]. The decrease of total phenols in the time post-inoculation confirms that the storage of fruits before processing is always a non-recommended practice even for the preservation of bioactive compounds.

\subsection{Multivariate Data Analysis}

After the individual analysis of the evolution of the various quality criteria, fatty acid composition, and total phenolic compound contents of Galega and Cobrançosa VOO samples, multivariate analysis was performed in order to identify the pattern behind the samples. Therefore, Principal Component Analysis (PCA) complemented by a Cluster Analysis (CA) were performed on the multivariate data where the VOO samples of each cultivar were characterised by 13 variables (acidity, FAME, FAEE, five sensory attributes, four major fatty acids and the total phenolic compounds content). 


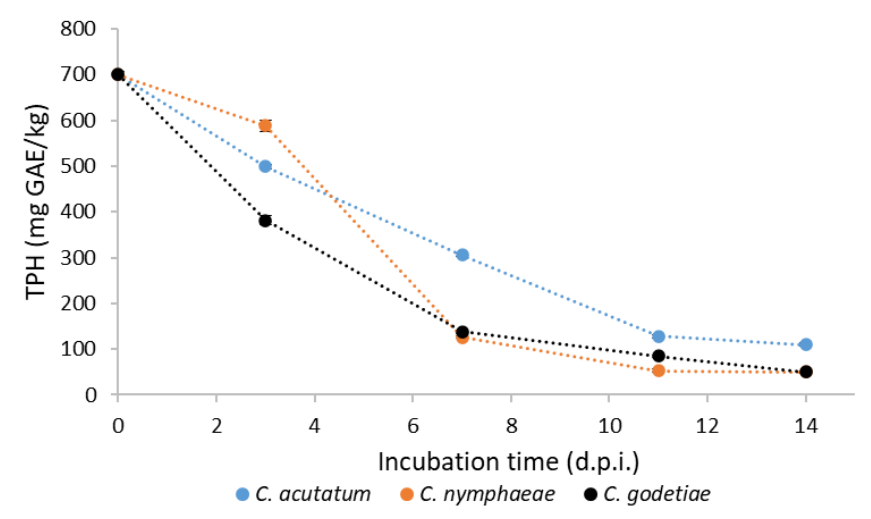

(a)

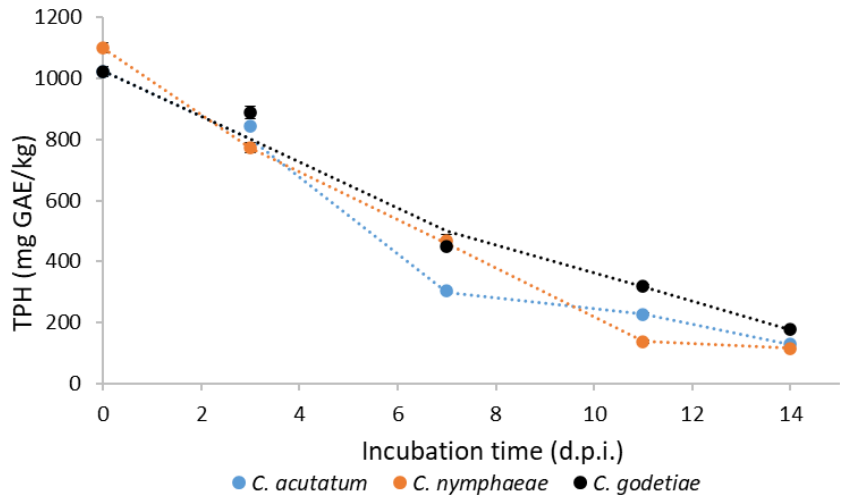

(b)

Figure 6. Total phenolic content (TPH), expressed in mg of gallic acid equivalent per $\mathrm{kg}$ of VOO (mg GAE/ $\mathrm{kg}$ ) in Galega (a) and Cobrançosa VOO (b) extracted from fruits inoculated with Colletotrichum acutatum, C. nymphaeae, and C. godetiae, at times $0,3,7,11$, and 14 days post-inoculation (d.p.i.) (mean values \pm STD; STD variation range: 2.47-20.59; hardly seen in the figures).

By PCA, it was possible to reduce the initial 13-dimension hyperspace to a plane defined by the first two principal components (new axis), containing 81.9 and $89.2 \%$ of the variance of the original data matrix for Galega and Cobrançosa VOO samples, respectively. The projection of the loadings of the original variables and VOO samples on these planes are shown in Figure 7. For both cultivars, the positive part of the first axis is highly correlated with positive sensory attributes (fruity, bitter, and pungent), oleic acid content (C18:1), and total phenols (TPH), while the negative part is highly correlated with the sensory defects (musty and winey), as well as with FFA, FAEE and FAME, and linoleic acid content (C18:2). Thus, the first axis can be identified as the "quality axis". Concerning the second principal component, it is mainly correlated with palmitic acid (C16:0) in Galega oils. For Cobrançosa oils, the second factor is not highly correlated with any of the original variables. It has rather low importance since it only accounts for $7.5 \%$ of the original variance of the data while the first accounts for $81.7 \%$.

For both cultivars, samples are spread along the first axis according to their quality, which increases from the negative to the positive side of the axis. Both initial Galega and Cobrançosa VOO ( $t_{0}$ samples) were highly correlated with the positive chemical and sensory attributes and higher contents of oleic acid. Galega VOO from fruits inoculated with C. acutatum or C. nymphaeae at 11 and 14 d.p.i. presented the highest FFA, FAEE, and FAME contents, and the highest scores in musty sensory defect, while VOO from fruits inoculated with C. godetiae presented the highest intensity in winey defect at 7, 11, and 14 d.p.i. Concerning Cobrançosa VOO, a similar trend was observed and VOO samples from fruits with 14 d.p.i. with C. nymphaeae or C. acutatum presented the lowest quality.

PCA is not a technique for grouping samples. Therefore, a hierarchical cluster analysis (CA) was performed on the same data sets for Galega and Cobrançosa VOO to evaluate the eventual presence of groups of similar samples suggested by PCA.

Figure 8 shows the hierarchical trees (dendrograms) for Galega and Cobrançosa VOO. At a linkage distance of around 150, it is possible to identify in the Galega VOO dendrogram the following groups of samples: Group 1 (Ac0, Go0, Ny0, Ac3, Ac7, Go3, and Ny3), Group 2 (Ny7, Go7, Go11, and Go14), and Group 3 (Ac11 and Ac14). The VOO Ny11 and Ny14 are not included in any group. For Cobrançosa VOO, the dendrogram shows two groups also at a linkage distance of 150: Group 1 (Ac0, Go0, Ny0, Ac3, Go3, and Ny3) and Group 2, containing all the other samples. For both cultivars, VOO from healthy fruits and fruits at 3 d.p.i. with C. acutatum (Ac), C. nymphaeae (Ny), and C. godetiae (Go) present similar properties. CA confirms that either Galega or Cobrançosa VOO samples are joined in different groups according to their quality. 

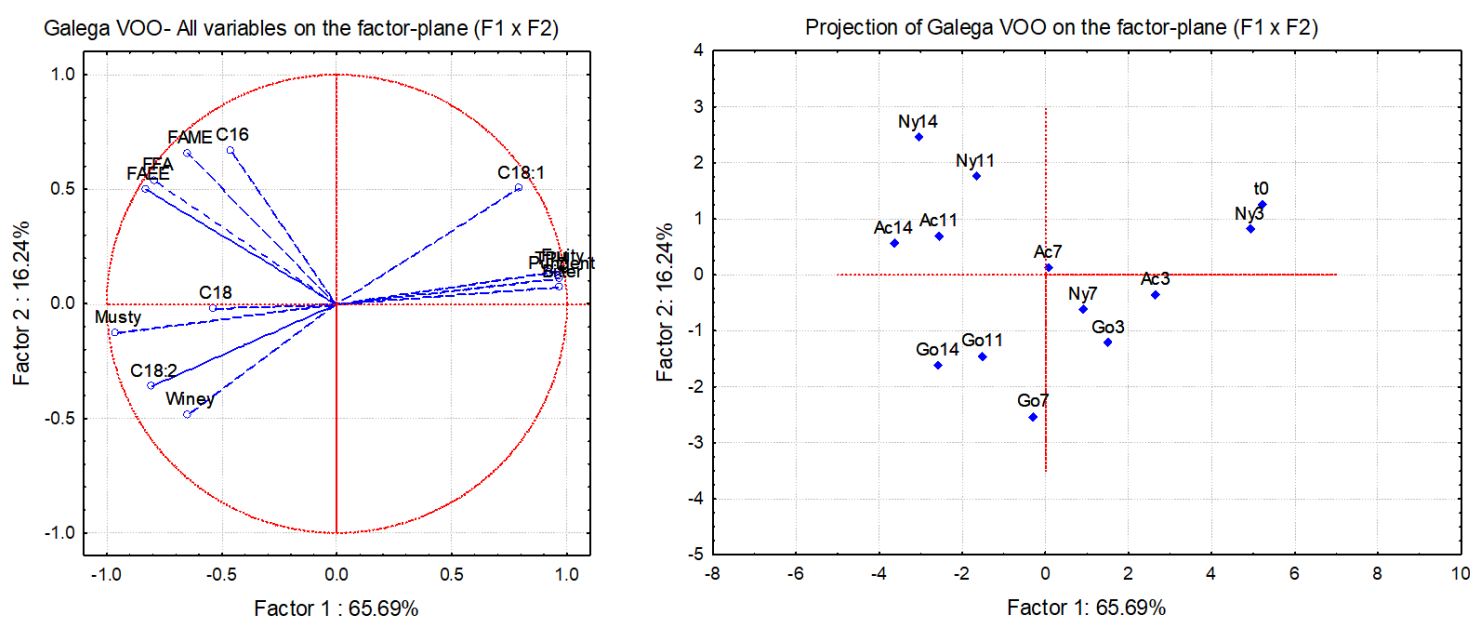

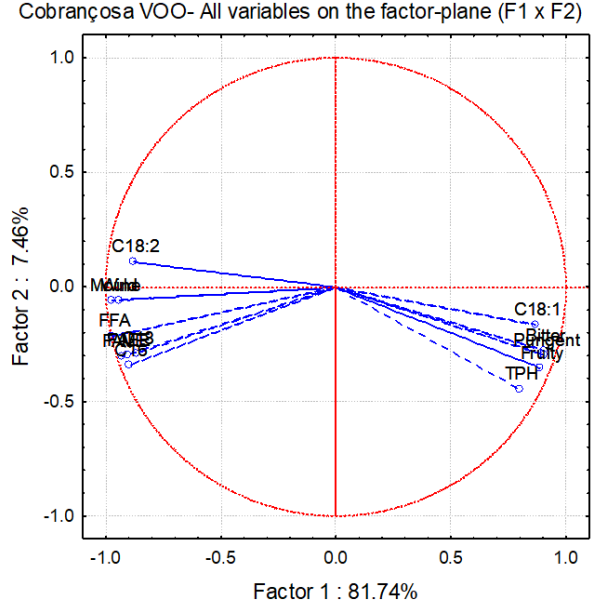

(a)

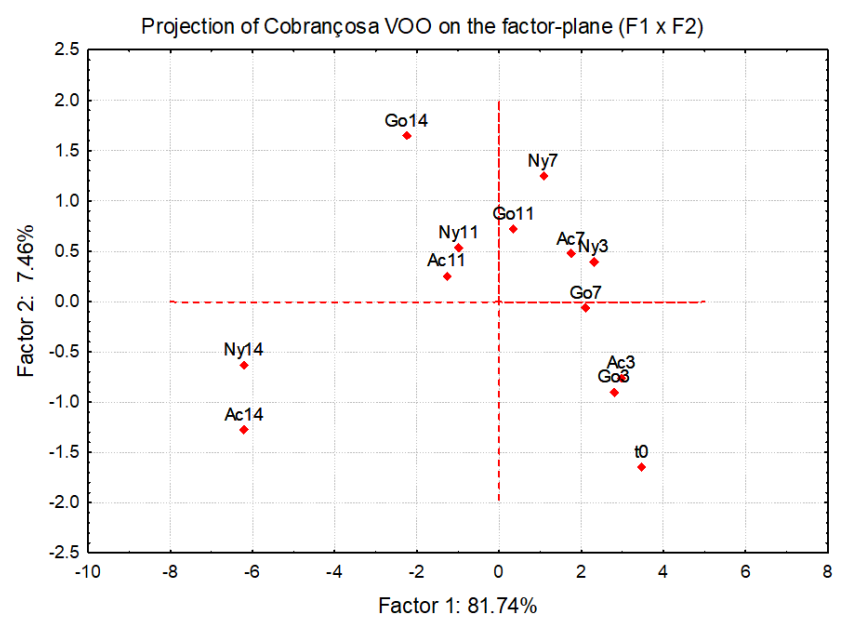

(b)

Figure 7. Projections of the loadings of the original variables (a) and Galega or Cobrançosa VOO samples (b) obtained from fruits inoculated with C. acutatum (Ac), C. nymphaeae (Ny), and C. godetiae (Go), at times 0, 3, 7, 11, and 14 d.p.i., on the planes defined by first and second factors (principal components). Variables: FFA- free fatty acids; FAEE- fatty acid ethyl esters; FAME- fatty acid methyl esters; TPH- total phenolic content; sensory scores: fruity, bitter, pungent, musty, and winey; fatty acids- C16:0, C18:0, C18:1, and C18:2).

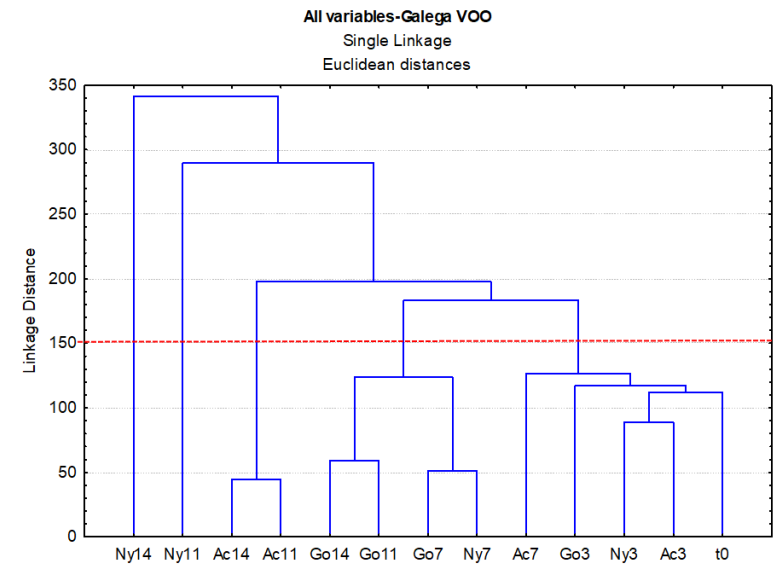

(a)

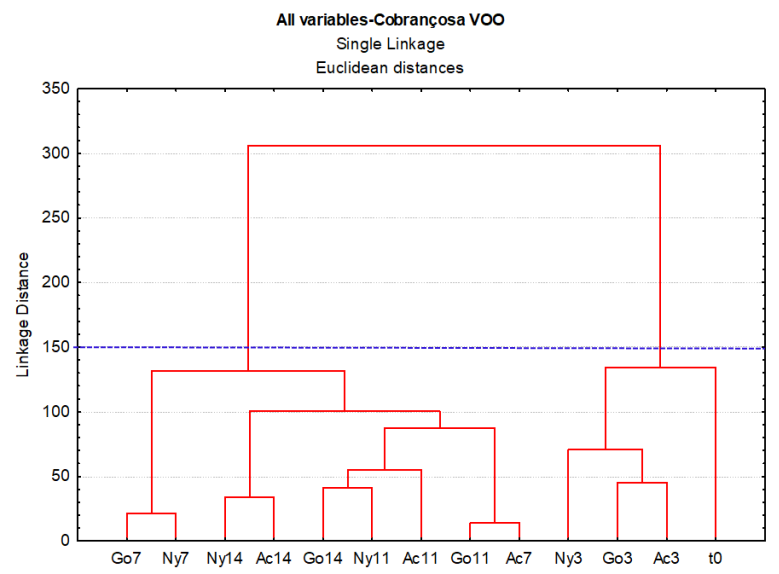

(b)

Figure 8. Dendrograms of Galega (a) and Cobrançosa VOO (b) samples obtained from fruits inoculated with C. acutatum (Ac), C. nymphaeae (Ny), and C. godetiae (Go), at times $0,3,7,11$, and 14 d.p.i., characterised by all the variables considered in Figure 7. 


\section{Conclusions}

This study confirmed C. acutatum and C. nymphaeae as more virulent than C. godetiae to olives. This is a cause of concern, as $C$. godetiae seems to be in the process of being replaced by the former two in several Mediterranean countries. This study also showed Galega Vulgar is more susceptible to Colletotrichum pathogens than Cobrançosa but with differences according to the fungal species. The combined effect of fungal species and olive cultivar on VOO quality parameters was dissected in the time post-inoculation.

In the present study, the assessment of sensory defects in the time after inoculation showed to be a more accurate tool to detect quality changes produced by each fungus than chemical analysis used as quality parameters for olive oil classification (acidity, peroxide value, UV absorbance, and FAEE content).

From a post-harvest point of view, this study also simulates the effects of olive storage before processing olive oil, when infected fruits even asymptomatic are harvested and stored. The disease evolves, and a few days after storage the effects can be dramatic for the quality of the oil, especially for the sensory characteristics and phenol content. The musty sensory defect was detected in olive oils obtained from Galega Vulgar or Cobrançosa fruits inoculated with C. nymphaeae or C. acutatum, at 3 d.p.i. or 7 d.p.i., respectively. Thus, defective olive oils are produced from Galega Vulgar fruits even at low disease incidence. Cobrançosa VOO, richer in phenolic compounds, present strong "green", "bitter", and "pungent" sensory notes, probably masking the defects during sensory evaluation.

Changes in anthracnose pathogen populations point towards the dissemination of the most virulent species. The present study showed that the presence of more virulent species, namely C. acutatum and C. nymphaeae, strongly promoted detrimental effects on olive oil quality even after short incubation periods. This is particularly important for more susceptible olive cultivars such as Galega Vulgar. In this context, climate change, with increased unpredictability, namely concerning the occurrence of periods of high humidity and mild temperatures, is a concern for the sustainable management of olive cultivation, harvesting, and processing for producing high-quality EVOO.

Author Contributions: The individual contributions of each co-author were as follows: Conceptualisation, F.P., P.T., H.O., and S.F.-D.; methodology, P.T., S.F.-D., and F.P.; formal analysis, H.A. (Hugo Afonso), H.A. (Helena Alegre), F.P., and P.T.; investigation resources, H.O.; data curation, F.P., P.T., and S.F.-D.; writing—original draft preparation: F.P. and S.F.-D.; writing-review and editing, S.F.-D., F.P., P.T., and H.O.; project administration, H.O.; funding acquisition, H.O. All authors have read and agreed to the published version of the manuscript.

Funding: This research was funded by the Fundação para a Ciência e a Tecnologia (FCT), Portugal through the research project PTDC/ASP-PLA/28547/2017.

Institutional Review Board Statement: Not applicable.

Informed Consent Statement: Not applicable.

Data Availability Statement: Data are available upon request to the authors.

Acknowledgments: The authors thank Cecilia Gouveia for the excellent technical assistance, and the Biotech Plant Lab of Beira Interior, Castelo Branco, Portugal, and the LEAF research unit (UID/AGR/04129/2021).

Conflicts of Interest: The authors declare no conflict of interest.

\section{References}

1. Graniti, A.; Faedda, R.; Cacciola, S.O.; San Lio, M. Olive diseases in a changing ecosystem. In Olive Diseases and Disorders; Schena, L., Agosteo, G.E., Cacciola, S.O., Eds.; Transworld Research Network: Kerala, India, 2011; pp. 1-31.

2. Kolainis, S.; Koletti, A.; Lykogianni, M.; Karamanou, D.; Gkizi, D.; Tjamos, S.E.; Paraskeuopoulos, A.; Aliferis, K.A. An integrated approach to improve plant protection against olive anthracnose caused by the Colletotrichum acutatum species complex. PLoS ONE 2020, 15, e0233916. [CrossRef]

3. Cacciola, S.O.; Faedda, R.; Sinatra, F.; Agosteo, G.E.; Schena, L.; Frisullo, S.; Magnano di San Lio, G. Olive anthracnose. J. Plant Pathol. 2012, 94, 29-44. [CrossRef] 
4. Talhinhas, P.; Gonçalves, E.; Sreenivasaprasad, S.; Oliveira, H. Virulence diversity of anthracnose pathogens (Colletotrichum acutatum and C. gloeosporioides species complexes) on eight olive cultivars commonly grown in Portugal. Eur. J. Plant Pathol. 2015, 142, 73-83. [CrossRef]

5. Moral, J.; Xaviér, C.J.; Viruega, J.R.; Roca, L.F.; Caballero, J.; Trapero, A. Variability in Susceptibility to Anthracnose in the World Collection of Olive Cultivars of Cordoba (Spain). Front. Plant Sci. 2017, 8, 1892. [CrossRef]

6. Talhinhas, P.; Loureiro, A.; Oliveira, H. Olive anthracnose: A yield- and oil quality-degrading disease caused by several species of Colletotrichum that differ in virulence, host preference and geographical distribution. Mol. Plant Pathol. 2018, 19, $1797-1807$. [CrossRef] [PubMed]

7. Antelmi, I.; Sion, V.; Nigro, F. First Report of Colletotrichum nymphaeae on Olive in Italy. Plant Dis. 2019, 103, 765. [CrossRef]

8. Carvalho, M.T.; Simoes-Lopes, P.; Silva, M.J.M. Influence of different olive infection rates of Colletotrichum acutatum on some important olive oil chemical parameters. Acta Hortic. 2008, 791, 555-559. [CrossRef]

9. Moral, J.; Xaviér, C.; Roca, L.F.; Romero, J.; Moreda, W.; Trapero, A. Olive Anthracnose and its effect on oil quality. Grasas Aceites 2014, 65, e028. [CrossRef]

10. Leoni, C.; Bruzzone, J.; Villamil, J.J.; Martínez, C.; Montelongo, M.J.; Bentancur, O.; Conde-Innamorato, P. Percentage of anthracnose (Colletotrichum acutatum s.s.) acceptable in olives for the production of extra virgin olive oil. Crop. Prot. 2018, 108, 47-53. [CrossRef]

11. Talhinhas, P.; Sreenivasaprasad, S.; Neves-Martins, J.; Oliveira, H. Molecular and phenotypic analyses reveal association of diverse Colletotrichum acutatum groups and a low level of C. gloeosporioides with olive anthracnose. Appl. Environ. Microbiol. 2005, 71, 2987-2998. [CrossRef]

12. Baroncelli, R.; Talhinhas, P.; Pensec, F.; Sukno, S.A.; Le Floch, G.; Thon, M.R. The Colletotrichum acutatum Species Complex as a Model System to Study Evolution and Host Specialization in Plant Pathogens. Front. Microbiol. 2017, 8, 2001. [CrossRef] [PubMed]

13. Schena, L.; Abdelfattah, A.; Mosca, S.; Li Destri Nicosia, M.G.; Agosteo, G.E.; Cacciola, S.O. Quantitative detection of Colletotrichum godetiae and C. acutatum sensu stricto in the phyllosphere and carposphere of olive during four phenological phases. Eur. J. Plant Pathol. 2017, 149, 337-347. [CrossRef]

14. EC. eAmbrosia-The EU Geographical Indications Register. Available online: https:/ / ec.europa.eu/info/food-farming-fisheries/ food-safety-and-quality/certification/quality-labels/geographical-indications-register/ (accessed on 30 March 2021).

15. Talhinhas, P.; Mota-Capitão, C.; Martins, S.; Ramos, A.P.; Neves-Martins, J.; Guerra-Guimarães, L.; Várzea, V.; Silva, M.C.; Sreenivasaprasad, S.; Oliveira, H. Epidemiology, histopathology and aetiology of olive anthracnose caused by Colletotrichum acutatum and C. gloeosporioides in Portugal. Plant Pathol. 2011, 60, 483-495. [CrossRef]

16. Damm, U.; Cannon, P.F.; Woudenberg, J.H.C.; Crous, P.W. The Colletotrichum acutatum species complex. Stud. Mycol. 2012, 73, 37-113. [CrossRef]

17. Official Journal of the European Union. European Union. Commission Regulation (EU) No 61/2011 Amending Regulation (EEC) No 2568/91 on the Characteristics of Olive Oil and Olive-Residue Oil and on the Relevant Methods of Analysis; Official Journal of the European Union: Brussels, Belgium, 2011; Volume L23, pp. 1-14. Available online: https:/ / eur-lex.europa.eu/LexUriServ/ LexUriServ.do?uri=OJ:L:2011:023:0001:0014:en:PDF (accessed on 30 March 2021).

18. Biedermann, M.; Bongartz, A.; Mariani, C.; Grob, K. Fatty acid methyl and ethyl esters as well as wax esters for evaluating the quality of olive oils. Eur. Food Res. Technol. 2008, 228, 65-74. [CrossRef]

19. Servili, M.; Montedoro, G. Contribution of phenolic compounds to virgin olive oil quality. Eur. J. Lipid Sci. Technol. 2002, 104, 602-613. [CrossRef]

20. Andrewes, P.; Busch, J.L.H.C.; Joode, T.; Groenewegen, A.; Alexandre, H. Sensory Properties of Virgin Olive Oil Polyphenols: Identification of Deacetoxy-ligstroside Aglycon as a Key Contributor to Pungency. J. Agric. Food Chem. 2003, 51, 1415-1420. [CrossRef]

21. Martín-Peláez, S.; Covas, M.I.; Fitó, M.; Kušar, A.; Pravst, I. Health effects of olive oil polyphenols: Recent advances and possibilities for the use of health claims. Mol. Nutr. Food Res. 2013, 57, 760-771. [CrossRef]

22. EFSA. EFSA Panel on Dietetic Products, Nutrition and Allergies (NDA); Scientific Opinion on the Substantiation of Health Claims Related to Polyphenols in Olive and Protection of LDL Particles from Oxidative Damage (ID 1333, 1638, 1639, 1696, 2865), Maintenance of Normal Blood HDL-Cholesterol Concentrations (ID 1639), Maintenance of Normal Blood Pressure (ID 3781), Anti-Inflammatory Properties (ID 1882), Contributes to the Upper Respiratory Tract Health (ID 3468), Can Help to Maintain a Normal Function of Gastrointestinal Tract (3779), and Contributes to Body Defences against External Agents (ID 3467) Pursuant to Article 13(1) of Regulation (EC) No 1924/2006. 2011. Available online: https:/ / www.efsa.europa.eu/en/efsajournal/pub/2033 (accessed on 30 March 2021).

23. Peres, F.; Martins, L.L.; Mourato, M.; Vitorino, C.; Ferreira-Dias, S. Bioactive Compounds of Portuguese Virgin Olive Oils Discriminate Cultivar and Ripening Stage. J. Am. Oil Chem. Soc. 2016, 93, 1137-1147. [CrossRef]

24. Moral, J.; Alsalimiya, M.; Roca, L.F.; Díez, C.M.; León, L.; de la Rosa, R.; Barranco, D.; Rallo, L.; Trapero, A. Relative Susceptibility of New Olive Cultivars to Spilocaea oleagina, Colletotrichum acutatum, and Pseudocercospora cladosporioides. Plant Dis. 2015, $99,58-64$. [CrossRef]

25. Gouvinhas, I.; Martins-Lopes, P.; Carvalho, T.; Barros, A.; Gomes, S. Impact of Colletotrichum acutatum Pathogen on Olive Phenylpropanoid Metabolism. Agriculture 2019, 9, 173. [CrossRef] 
26. Moral, J.; Bouhmidi, K.; Trapero, A. Influence of Fruit Maturity, Cultivar Susceptibility, and Inoculation Method on Infection of Olive Fruit by Colletotrichum acutatum. Plant Dis. 2008, 92, 1421-1426. [CrossRef] [PubMed]

27. Gouvinhas, I.; Domínguez-Perles, R.; Gironés-Vilaplana, A.; Carvalho, T.; Machado, N.; Barros, A. Kinetics of the Polyphenolic Content and Radical Scavenging Capacity in Olives through On-Tree Ripening. J. Chem. 2017, 2017, 5197613. [CrossRef]

28. Peel, M.C.; Finlayson, B.L.; McMahon, T.A. Updated world map of the Köppen-Geiger climate classification. Hydrol. Earth Syst. Sci. 2007, 11, 1633-1644. [CrossRef]

29. IPMA. Normais Climatológicas-1981-2010 (Provisórias)—Castelo Branco. Available online: https://www.ipma.pt/pt/oclima/ normais.clima/1981-2010/005/ (accessed on 10 January 2021).

30. IOC. Guide for the Determination of the Characteristics of Oil-Olives. COI/OH/Doc. N N $^{\circ}$. 2011. Available online: https: //www.internationaloliveoil.org/wp-content/uploads/2019/11/COI-OH-Doc.-1-2011-Eng.pdf (accessed on 30 March 2021).

31. Peres, F.; Martins, L.L.; Ferreira-Dias, S. Laboratory-scale optimization of olive oil extraction: Simultaneous addition of enzymes and microtalc improves the yield. Eur. J. Lipid Sci. Technol. 2014, 116, 1054-1062. [CrossRef]

32. Angerosa, F. Influence of volatile compounds on virgin olive oil quality evaluated by analytical approaches and sensor panels Eur. J. Lipid Sci. Technol. 2002, 104, 639-660. [CrossRef]

33. Official Journal of the European Union. Commission Implementing Regulation (EU) No 1348/2013 of 16 December 2013 amending Regulation (EEC) No 2568/91 on the Characteristics of Olive Oil and Olive-Residue Oil and on the Relevant Methods of Analysis; Official Journal of the European Union: Brussels, Belgium, 2013; Volume L338, pp. 31-67. Available online: https: / / eur-lex.europa.eu/ legal-content/GA/TXT/?uri=CELEX:32013R1348 (accessed on 30 March 2021).

34. Pizarro, M.L.; Becerra, M.; Sayago, A.; Beltrán, M.; Beltrán, R. Comparison of Different Extraction Methods to Determine Phenolic Compounds in Virgin Olive Oil. Food Anal. Methods 2013, 6, 123-132. [CrossRef]

35. Miller, J.C.; Miller, J.N. Statistics for Analytical Chemistry; Ellis Horwood and Prentice Hall: Chichester, UK, 1993.

36. Jolliffe, I.T. Principal Component Analysis, 2nd ed.; Springer: New York, NY, USA, 2002.

37. Gomes, S.; Bacelar, E.; Martins-Lopes, P.; Carvalho, T.; Guedes-Pinto, H. Infection process of olive fruits by Colletotrichum acutatum and the protective role of the cuticle and epidermis. J. Agric. Sci. 2012, 4, 101. [CrossRef]

38. Mafra, I.; Barros, A.S.; Nunes, C.; Vitorino, R.; Saraiva, J.; Smith, A.C.; Waldron, K.W.; Delgadillo, I.; Coimbra, M.A. Ripeningrelated changes in the cell walls of olive (Olea europaea L.) pulp of two consecutive harvests. J. Sci. Food Agric. 2006, 86, 988-998. [CrossRef]

39. Machado, M.; Felizardo, C.; Fernandes-Silva, A.A.; Nunes, F.M.; Barros, A. Polyphenolic compounds, antioxidant activity and 1-phenylalanine ammonia-lyase activity during ripening of olive cv. "Cobrançosa" under different irrigation regimes. Food Res. Int. 2013, 51, 412-421. [CrossRef]

40. Sousa, C.; Gouvinhas, I.; Barreira, D.; Carvalho, M.T.; Vilela, A.; Lopes, J.; Martins-Lopes, P.; Barros, A.I. 'Cobrançosa' Olive Oil and Drupe: Chemical Composition at Two Ripening Stages. J. Am. Oil Chem. Soc. 2014, 91, 599-611. [CrossRef]

41. Official Journal of the European Union. Commission Delegated Regulation (EU) No 2019/1604 of 27 September 2019 Amending Regulation (EEC) No 2568/91 on the Characteristics of Olive Oil and Olive-Residue Oil and on the Relevant Methods of Analysis; Official Journal of the European Union: Brussels, Belgium, 2019; Volume L250, pp. 14-48. Available online: https:/ / eur-lex.europa.eu/ legal-content/EN/TXT/PDF/?uri=CELEX:32019R1604\&from=EN (accessed on 30 March 2021).

42. Runcio, A.; Sorgonà, L.; Mincione, A.; Santacaterina, S.; Poiana, M. Volatile compounds of virgin olive oil obtained from Italian cultivars grown in Calabria.: Effect of processing methods, cultivar, stone removal, and antracnose attack. Food Chem. 2008, 106, 735-740. [CrossRef]

43. Frankel, E.N. Chemistry of Extra Virgin Olive Oil: Adulteration, Oxidative Stability, and Antioxidants. J. Agric. Food Chem. 2010, 58, 5991-6006. [CrossRef]

44. Fakas, S.; Kefalogianni, I.; Makri, A.; Tsoumpeli, G.; Rouni, G.; Gardeli, C.; Papanikolaou, S.; Aggelis, G. Characterization of olive fruit microflora and its effect on olive oil volatile compounds biogenesis. Eur. J. Lipid Sci. Technol. 2010, 112, 1024-1032. [CrossRef]

45. Cayuela, J.A.; Gómez-Coca, R.B.; Moreda, W.; Pérez-Camino, M.C. Sensory defects of virgin olive oil from a microbiological perspective. Trends Food Sci. Technol. 2015, 43, 227-235. [CrossRef]

46. Circi, S.; Capitani, D.; Randazzo, A.; Ingallina, C.; Mannina, L.; Sobolev, A.P. Panel test and chemical analyses of commercial olive oils: A comparative study. Chem. Biol. Technol. Agric. 2017, 4, 18. [CrossRef]

47. Kirsch, C.; Hahlbrock, K.; Somssich, I.E. Rapid and Transient Induction of a Parsley Microsomal [delta]12 Fatty Acid Desaturase mRNA by Fungal Elicitor. Plant Physiol. 1997, 115, 283-289. [CrossRef] [PubMed]

48. Madi, L.; Wang, X.; Kobiler, I.; Lichter, A.; Prusky, D. Stress on avocado fruits regulates $\Delta$ 9-stearoyl ACP desaturase expression, fatty acid composition, antifungal diene level and resistance to Colletotrichum gloeosporioides attack. Physiol. Mol. Plant Pathol. 2003, 62, 277-283. [CrossRef]

49. Kazaz, S.; Miray, R.; Baud, S. Acyl-Acyl Carrier Protein Desaturases and Plant Biotic Interactions. Cells 2021, 10, 674. [CrossRef] [PubMed]

50. Guilengue, N.; Neves-Martins, J.; Talhinhas, P. Response to Anthracnose in a Tarwi (Lupinus mutabilis) Collection Is Influenced by Anthocyanin Pigmentation. Plants 2020, 9, 583. [CrossRef] [PubMed]

51. Roy, S.; Nuckles, E.; Archbold, D.D. Effects of Phenolic Compounds on Growth of Colletotrichum spp. In Vitro. Curr. Microbiol. 2018, 75, 550-556. [CrossRef] [PubMed] 
52. Lattanzio, V.; Lattanzio, V.M.T.; Cardinali, A. Role of phenolics in the resistance mechanisms of plants against fungal pathogens and insects. Phytochem. Adv. Res. 2006, 661, 23-67.

53. Mendonça, E.; Martins, A.; Anselmo, A.M. Biodegradation of natural phenolic compounds as single and mixed substrates by Fusarium flocciferum. Electron. J. Biotechnol. 2004, 7, 30-37. [CrossRef]

54. Martínková, L.; Kotik, M.; Marková, E.; Homolka, L. Biodegradation of phenolic compounds by Basidiomycota and its phenol oxidases: A review. Chemosphere 2016, 149, 373-382. [CrossRef] [PubMed] 